\title{
Impact of misplaced subclavian vein catheter into jugular vein on transpulmonary thermodilution measurement variables"
}

\author{
Wen-qiao YU ${ }^{\S \dagger 1}$, Yun ZHANG ${ }^{\S 1}$, Shao-yang ZHANG ${ }^{1}$, Zhong-yan LIANG ${ }^{2}$, \\ Shui-qiao $\mathrm{FU}^{1}$, Jia XU ${ }^{3}$, Ting-bo LIANG ${ }^{\dagger 1}$ \\ ('Department of Hepatobiliary and Pancreatic Surgery and Intensive Care Unit, the Second Affiliated Hospital, \\ School of Medicine, Zhejiang University, Hangzhou 310021, China) \\ ( ${ }^{2}$ Women's Hospital, School of Medicine, Zhejiang University, Hangzhou 310006, China) \\ ( ${ }^{3}$ Department of Emergency, the First Affiliated Hospital, School of Medicine, Zhejiang University, Hangzhou 310003, China) \\ ‘E-mail: yuwenqiao_60@hotmail.com; liangtingbo@zju.edu.cn \\ Received July 9, 2015; Revision accepted Nov. 7, 2015; Crosschecked Dec. 16, 2015
}

\begin{abstract}
Objective: The subclavian vein (SCV) is usually used to inject the indicator of cold saline for a transpulmonary thermodilution (TPTD) measurement. The SCV catheter being misplaced into the internal jugular (IJV) vein is a common occurrence. The present study explores the influence of a misplaced SCV catheter on TPTD variables. Methods: Thirteen severe acute pancreatitis (SAP) patients with malposition of the SCV catheter were enrolled in this study. TPTD variables including cardiac index (CI), global end-diastolic volume index (GEDVI), intrathoracic blood volume index (ITBVI), and extravascular lung water index (EVLWI) were obtained after injection of cold saline via the misplaced SCV catheter. Then, the misplaced SCV catheter was removed and IJV access was constructed for a further set of TPTD variables. Comparisons were made between the TPTD results measured through the IJV and misplaced SCV accesses. Results: A total of 104 measurements were made from TPTD curves after injection of cold saline via the IJV and misplaced SCV accesses. Bland-Altman analysis demonstrated an overestimation of $+111.40 \mathrm{ml} / \mathrm{m}^{2}$ (limits of agreement: 6.13 and $216.70 \mathrm{ml} / \mathrm{m}^{2}$ ) for GEDVI and ITBVI after a misplaced SCV injection. There were no significant influences on $\mathrm{Cl}$ and EVLWI. The biases of $+0.17 \mathrm{~L} /\left(\mathrm{min} \cdot \mathrm{m}^{2}\right)$ for $\mathrm{Cl}$ and $+0.17 \mathrm{ml} / \mathrm{kg}$ for EVLWI were revealed by Bland-Altman analysis. Conclusions: The malposition of an SCV catheter does influence the accuracy of TPTD variables, especially GEDVI and ITBVI. The position of the SCV catheter should be confirmed by chest X-ray in order to make good use of the TPTD measurements.
\end{abstract}

Key words: Transpulmonary thermodilution, Jugular vein catheter, Misplaced subclavian vein catheter, Severe acute pancreatitis

http://dx.doi.org/10.1631/jzus.B1500167

CLC number: R472

\section{Introduction}

The transpulmonary thermodilution (TPTD)

\footnotetext{
"Corresponding author

$\S$ The two authors contributed equally to this work

* Project supported by the National Natural Science Foundation of China (Nos. 81501644, 81471623, 81130007, 81270446, and 30801188) and the Key Science and Technology Innovation Team Project of the Science and Technology Department of Zhejiang Province (No. 2011R50018-16), China

(D) ORCID: Wen-qiao YU, http://orcid.org/0000-0003-3940-2237

(c) Zhejiang University and Springer-Verlag Berlin Heidelberg 2016
} technique is a multi-parametric advanced cardiopulmonary monitoring technique that enables measurement of important variables required for making decisions in critically ill patients (Della Rocca et al., 2002; 2007; Heid et al., 2008; Cannesson et al., 2011; Vincent et al., 2011; Sakka et al., 2012). The TPTD is based on a cold saline bolus injection through a central venous catheter $(\mathrm{CVC})$ in the central venous 
circulation, and the subsequent blood temperature change is picked up by a thermistor placed in the descending aorta through the femoral artery. Three main values, i.e. the area under curve (AUC), mean transit time (MTt), and down-slope time (DSt), are determined by the created thermodilution curve. MTt means the time that half of the injected cold saline has passed the thermistor, and DSt means the duration of the exponential decrease of the dilution curve (Sakka et al., 1999; Reuter et al., 2005). Cardiac output (CO), global end-diastolic volume (GEDV), intra-thoracic blood volume (ITBV), and extra-vascular lung water (EVLW) are calculated according to the three values described above: both GEDV and ITBV are the preload indicators, and EVLW is a sensitive indicator of pulmonary edema (Katzenelson et al., 2004; Michard et al., 2005; Kuzkov et al., 2006; Khan et al., 2007; Bendjelid et al., 2010; Belda et al., 2011; Eichhorn et al., 2012; Kiefer et al., 2012). The combined measurement of CO, GEDV, and EVLW could provide a synthetic platform for hemodynamic management in critically ill patients.

Using superior vena cava via subclavian or jugular catheters is the preferred method for injecting the cold saline bolus for TPTD. A recent guideline recommends subclavian vein (SCV) access due to a lower catheter infection rate (O'Grady et al., 2011). However, misplacement of the catheter into the ipsilateral internal jugular vein (IJV) might occur during right subclavian cannulation (Rath et al., 2009). Sometimes, the misplacement is detected promptly, for a variety of reasons such as delayed chest radiography, weak awareness of clinicians of the importance of the correct catheter position. So far, to the best of our knowledge, no study has been reported on whether the misplaced catheter has influence on the TPTD measurements. Over the past two years, we collected data on 13 patients with misplacement into the ipsilateral IJV on severe acute pancreatitis (SAP) patients, who need hemodynamic monitoring, and made a series of case studies.

The aim of the present study is to investigate the influence of misplayed SCV catheter into IJV on TPTD measurements including cardiac index (CI), GEDV index (GEDVI), ITBVI index (ITBVI), and EVLW index (EVLWI). The study has been approved by Ethics Committee of the Second Affiliated Hospital, School of Medicine, Zhejiang University (Hangzhou, China).

\section{Materials and methods}

\subsection{Patients}

According to the Revision of Atlanta Classification of Acute Pancreatitis (Banks et al., 2013), 97 SAP patients were diagnosed and admitted into intensive care unit of the Second Affiliated Hospital, School of Medicine, Zhejiang University (Hangzhou, China) between September 2012 and August 2014. Most of them were cholangitis-originated and other reasons were alcohol abuse and hyperlipidemia. Among those patients, 13 were had the SCV catheter misplaced into the IJV and received TPTD measuring. All of the TPTD measurements were analyzed from these 13 SAP patients.

\subsection{TPTD measurements}

All 13 patients had an SCV cava, and TPTD was performed when the misplaced SCV catheter was detected by chest X-ray (Fig. 1a). The misplaced SCV catheter was then removed and the ipsilateral IJV catheter was then replaced and confirmed by chest X-ray before another TPTD measurement was performed (Fig. 1b). The maximum interval time between the two different catheter measurements is 20 min. Central venous pressure (CVP) was recorded though the two venous catheter. TPTD measurements were performed using a Pulsiocath 5-French thermistortipped catheter (Pulsion Medical Systems, Munich, Germany) placed in the abdominal aorta through the femoral artery and connected to the PiCCO Plus monitor (Pulsion Medical Systems SE, Feldkirchen, Germany). According to the manufacturer's recommendations, a $15-\mathrm{ml}$ cold saline $\left(0-4{ }^{\circ} \mathrm{C}\right)$ solution was injected into the circulation through the SCV and IJV catheter distal lumen, respectively. A total of 104 measurements were obtained (52 measurements via

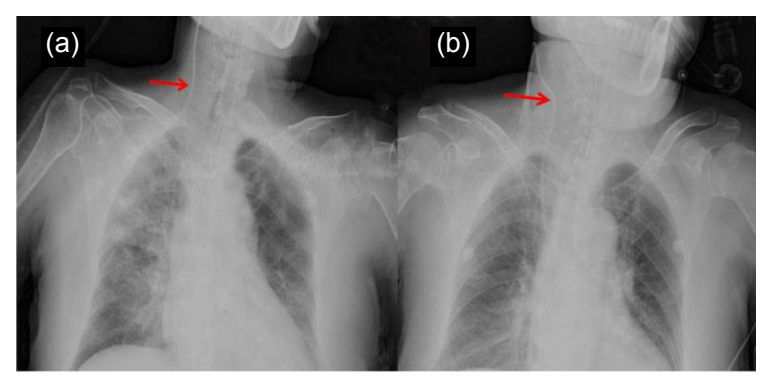

Fig. 1 (a) Subclavian vein catheter was misplaced into internal jugular vein (arrow); (b) jugular vein catheter was replaced (arrow) 
misplaced SCV access and another 52 measurements via IJV access). One THTD measurement procedure consisted of four injections via each catheter access. Results were calculated as the mean of these four consecutive measurements. There was no intervention allowed during the two different catheter access measurement procedures. CO, GEDV, and ITBV were indexed for body surface area and EVLW was indexed for body weight.

\subsection{Statistical analysis}

All results were expressed as mean \pm standard deviation (SD) and analyzed by statistical software GraphPad Prism version 6.0 (GraphPad Software for Science, San Diego, CA, USA). The differences of TPTD parameters derived from subclavian and jugular injection were compared though Bland-Altman analysis. Systematic bias and $95 \%$ limits of agreement were used for comparison of CI, GEDVI, ITBVI, and EVLWI. AUC, MTt, and DSt were compared using the two-tailed paired Student's $t$-test; $P<0.05$ was considered to indicate a significant difference.

\section{Results}

\subsection{Patients' characteristics}

A total of 104 measurements in 13 SAP patients admitted to ICU were analyzed. All patients had persistent organ failure and the characteristics are shown in Table 1.

\subsection{Patients' basic cardiopulmonary characteris- tics and TPTD measurements}

Two groups of TPTD measurements were calculated from TPTD curves after injection of cold saline via the IJV and the misplaced SCV accesses. Patients' basic cardiopulmonary characteristics and TPTD variables data related to different vascular access are shown in Table 2.

The comparison of GEDVI $\mathrm{IJV}_{\mathrm{JV}}$ and GEDVI $\mathrm{ISV}_{\mathrm{SC}-\mathrm{IJV}}$ (SCV-IJV: misplaced SCV catheter into IJV) shows that the value of GEDVI $\mathrm{IJV}_{\mathrm{JV}}$ and GEDVI $\mathrm{SCV}_{\mathrm{SC} \text {-IJV }}$ ranged from 432.0 to $1484.0 \mathrm{ml} / \mathrm{m}^{2}$ (mean $(852.1 \pm$ 256.1) $\mathrm{ml} / \mathrm{m}^{2}$ ). Bland-Altman analysis showed an overestimation of GEDVI after misplaced subclavian injection (Fig. 2a). The bias was $+111.40 \mathrm{ml} / \mathrm{m}^{2}$ and the $95 \%$ limits of agreement were +6.13 and $+216.70 \mathrm{ml} / \mathrm{m}^{2}$ (Fig. 2a). ITBVI is proportional to
GEDVI and is calculated according to the formula: ITBVI $=1.25 \times$ GEDVI. Therefore, the bias of ITBVI was similar to GEDVI.

Table 1 Characteristics of the patients

\begin{tabular}{lc}
\hline \multicolumn{1}{c}{ Characteristics } & Value $^{*}$ \\
\hline Sex (male:female) & $8: 5$ \\
Age (year) & $55.3 \pm 14.4(31.0-79.0)$ \\
Weight $(\mathrm{kg})$ & $73.6 \pm 10.4(58.5-95.0)$ \\
Height $(\mathrm{cm})$ & $175.5 \pm 5.3(167.0-184.0)$ \\
Body surface area $\left(\mathrm{m}^{2}\right)$ & $1.81 \pm 0.18(1.48-2.13)$ \\
Body mass index $\left(\mathrm{kg} / \mathrm{m}^{2}\right)$ & $16.47 \pm 4.20(13.28-27.93)$ \\
APACHE II score & $16.69 \pm 5.07(9.00-25.00)$ \\
Organ failure & $12(92.3 \%)$ \\
$\quad$ Acute respiratory distress & \\
$\quad$ syndrome & $6(46.2 \%)$ \\
$\quad$ Acute kidney injury & $5(38.5 \%)$ \\
Shock & $6(46.2 \%)$ \\
Abdominal compartment & \\
$\quad$ syndrome & $12(92.3 \%)$ \\
ICU survival &
\end{tabular}

APACHE II: acute physiology and chronic health evaluation II; ICU: intensive care unit. " Data are expressed as mean $\pm \mathrm{SD}$ (range) or number (percentage)

Table 2 Patients' cardiopulmonary characteristics

\begin{tabular}{lc}
\hline \multicolumn{1}{c}{ Characteristics } & Value $^{*}$ \\
\hline Heart rate $($ beats $/ \mathrm{min})$ & $102.8 \pm 17.1(78.0-141.0)$ \\
Mean arterial pressure & $66.7 \pm 8.1(55.0-82.0)$ \\
$\quad(\mathrm{mmHg})$ & $15.2 \pm 5.4(7.0-26.0)$ \\
$\mathrm{CVP}_{\mathrm{IJV}}(\mathrm{mmHg})$ & $14.5 \pm 5.6(5.0-25.0)$ \\
$\mathrm{CVP}_{\mathrm{SCV}-\mathrm{IJV}}(\mathrm{mmHg})$ & $14.8 \pm 5.3(5.0-26.0)$ \\
$\mathrm{CVP}_{\mathrm{AVG}}(\mathrm{mmHg})$ & $3.52 \pm 0.98(1.70-5.60)$ \\
$\mathrm{CI}_{\mathrm{IJV}}\left(\mathrm{L} /\left(\mathrm{min} \cdot \mathrm{m}^{2}\right)\right)$ & $3.69 \pm 0.92(1.80-5.50)$ \\
$\mathrm{CI}_{\mathrm{SCV}-\mathrm{IJV}}\left(\mathrm{L} /\left(\mathrm{min} \cdot \mathrm{m}^{2}\right)\right)$ & $3.60 \pm 0.95(1.70-5.60)$ \\
$\mathrm{CI}_{\mathrm{AVG}}\left(\mathrm{L} /\left(\mathrm{min} \cdot \mathrm{m}^{2}\right)\right)$ & $10.26 \pm 5.23(3.00-20.00)$ \\
$\mathrm{EVLWI}_{\mathrm{IJV}}(\mathrm{ml} / \mathrm{kg})$ & $10.43 \pm 5.19(4.00-21.00)$ \\
$\mathrm{EVLWI}_{\mathrm{SCV}-\mathrm{IJV}}(\mathrm{ml} / \mathrm{kg})$ & $10.34 \pm 5.18(3.00-21.00)$ \\
$\mathrm{EVLWI}_{\mathrm{AVG}}(\mathrm{ml} / \mathrm{kg})$ & $796.4 \pm 235.1(432.0-1310.0)$ \\
$\mathrm{GEDVI}_{\mathrm{IJV}}\left(\mathrm{ml} / \mathrm{m}^{2}\right)$ & $907.8 \pm 266.2(498.0-1484.0)$ \\
$\mathrm{GEDVI}_{\mathrm{SCV}-\mathrm{IJV}}\left(\mathrm{ml} / \mathrm{m}^{2}\right)$ & $852.1 \pm 256.1(432.0-1484.0)$ \\
$\mathrm{GEDVI}_{\mathrm{AVG}}\left(\mathrm{ml} / \mathrm{m}^{2}\right)$ &
\end{tabular}

$\mathrm{CVP}_{\text {IJV }}$ : central venous pressure of jugular; $\mathrm{CVP}_{\mathrm{SCV}-\mathrm{IJV}}$ : central venous pressure of misplaced access; $\mathrm{CVP}_{\mathrm{AVG}}$ : average of jugular and misplaced access central venous pressure; $\mathrm{CI}_{\mathrm{IJV}}$ : cardiac output index of jugular; $\mathrm{CVP}_{\mathrm{SCV}-\mathrm{IJV}}$ : cardiac output index of misplaced access; $\mathrm{CI}_{\mathrm{AVG}}$ : average of jugular and misplaced access cardiac output index; EVLWI IJV: extra-vascular lung water index of jugu-

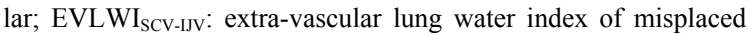
access; EVLWI $\mathrm{AVG}_{\mathrm{A}}$ : average of jugular and misplaced access extravascular lung water index; $\mathrm{GEDVI}_{\mathrm{IJV}}$ : global end-diastolic volume

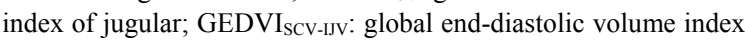
of misplaced access; $\mathrm{GEDVI}_{\mathrm{AVG}}$ : average of jugular and misplaced access global end-diastolic volume index. ${ }^{*}$ Data are expressed as mean $\pm \mathrm{SD}$ (range). $1 \mathrm{mmHg}=133.3 \mathrm{~Pa}$ 

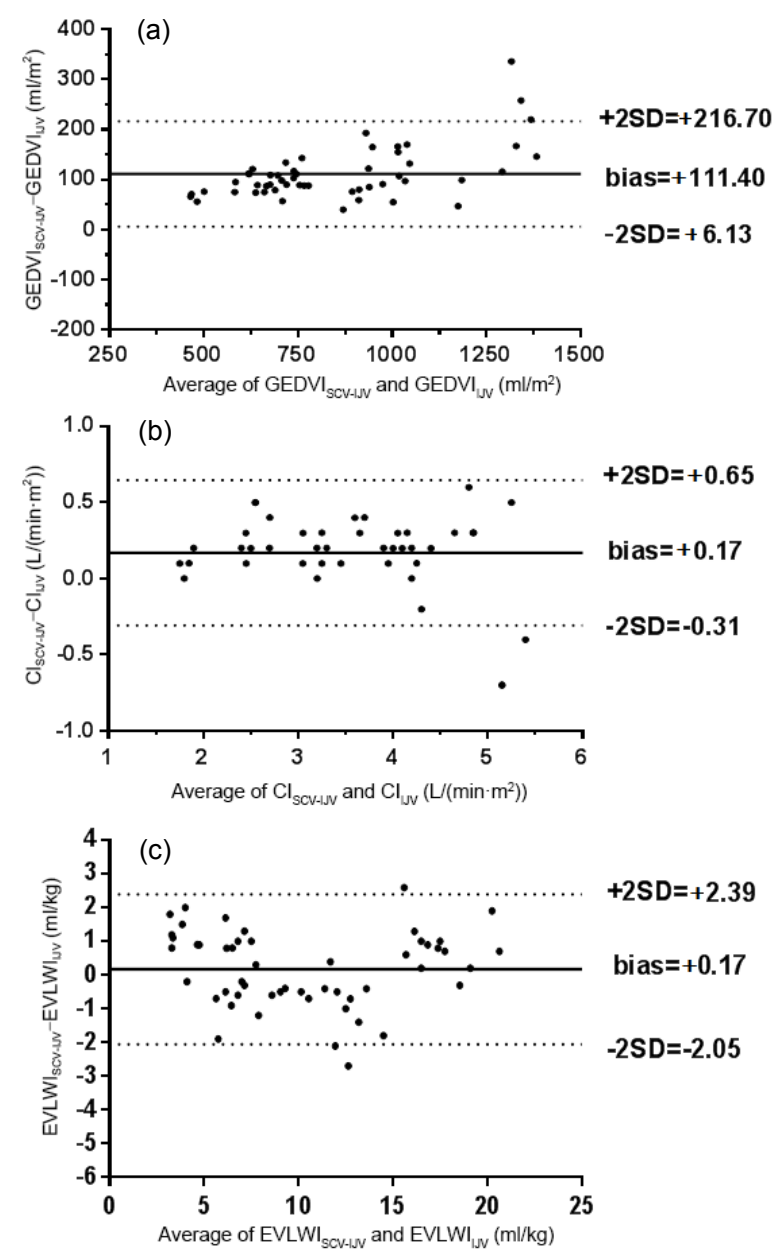

Fig. 2 Transpulmonary thermodilution after jugular $\left(\right.$ GEDVI IJV $_{\text {IJV }}, \mathrm{CI}_{\text {IJV }}$, EVLWI $\left._{\text {IJV }}\right)$ and misplaced access

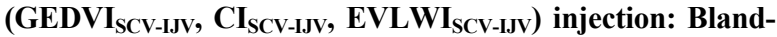
Altman analysis of global end-diastolic volume index (a), cardiac output index (b), and extra-vascular lung water index (c)

The solid lines indicate the mean difference between variables after jugular and misplaced access injection. The dotted lines indicate the $95 \%$ limits of agreement $( \pm 2 \mathrm{SD})$
The comparison of $\mathrm{CI}_{\mathrm{IJV}}$ and $\mathrm{CI}_{\mathrm{SCV}-I J V}$ indicated an acceptable level of agreement. The value of $\mathrm{CI}_{\mathrm{IJV}}$ and $\mathrm{CI}_{\mathrm{SCV}-\mathrm{IJV}}$ ranged from 1.70 to $5.60 \mathrm{~L} /\left(\mathrm{min} \cdot \mathrm{m}^{2}\right)$ (mean $\left.(3.60 \pm 0.95) \mathrm{L} /\left(\min \cdot \mathrm{m}^{2}\right)\right)$. Bland-Altman analysis revealed a bias of $+0.17 \mathrm{~L} /\left(\mathrm{min} \cdot \mathrm{m}^{2}\right)$ (Fig. $\left.2 \mathrm{~b}\right)$, the $95 \%$ limits of agreement were -0.31 and $+0.65 \mathrm{~L} /\left(\min \cdot \mathrm{m}^{2}\right)$ (Fig. 2b).

The value of $E{ }^{2} W_{I J V}$ and $E_{\text {EVWI }}$ SCV-IJV ranged from 3.00 to $21.00 \mathrm{ml} / \mathrm{kg}$ (mean (10.34 5.18) $\mathrm{ml} / \mathrm{kg}$ ). EVLWI SCV-IJV $_{\text {showed a good agree- }}$ ment with EVLWI $_{\text {IJV. }}$ A bias of $+0.17 \mathrm{ml} / \mathrm{kg}$ was indicated by Bland-Altman analysis (Fig. 2c), and the $95 \%$ limits of agreement were -2.05 and $+2.39 \mathrm{ml} / \mathrm{kg}$ (Fig. 2c).

There is a significant difference of MTt between jugular injection and misplaced subclavian injection. MTt after injection into misplaced SCV access (MTt $\left.\mathrm{MCV}_{\mathrm{SCIV}}\right)$ (mean $(23.77 \pm 5.28) \mathrm{s}$ ) is longer than MTt after jugular $\left(\mathrm{MTt}_{\mathrm{IJV}}\right)$ injection (mean $(21.15 \pm$ 5.62) s) ( $P=0.016$; Fig. 3a). We can speculate that this is the main reason leading to overestimation of GEDVI and ITBVI. However, there are no statistical differences of AUC or DSt between jugular injection and misplaced subclavian injection (Figs. 3b and 3c).

\section{Discussion}

The SCV is usually used for catheter placement, and the most common misplacement during SCV catheterization is into the IJV. The question is whether the injection of cold saline through a misplaced SCV catheter into the IJV has influence on TPTD measurement. In TPTD measurement, previous studies have found that an overestimation of
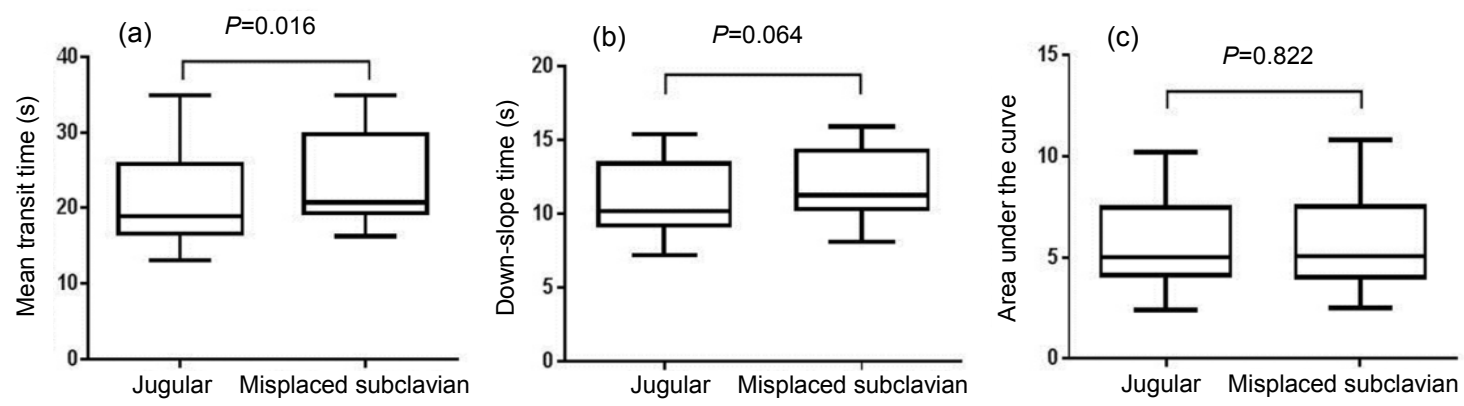

Fig. 3 Statistical comparison of mean transit time (a), down-slope time (b), and area under the curve (c) after jugular and misplaced access injection 
GEDVI was indicated after femoral vein injection compared with the jugular vein injection (Schmidt et al., 2007; Saugel et al., 2010). We also found that the injection of an indicator of cold saline via misplaced SCV access can lead to regular abnormalities in GEDVI and ITBVI.

The present study reveals that there is an acceptable level of agreement of CI and EVLWI between jugular and misplaced SCV catheter injection. However, for GEDVI and ITBVI, we found a significant bias that shows an overestimation of results obtained after misplaced SCV catheter injection. Our results also showed that the MTt after misplaced catheter injection ( $\left.\mathrm{MTt}_{\mathrm{SCV}-\mathrm{IJV}}\right)$ is higher than that with jugular injection $\left(\mathrm{MTt}_{\mathrm{IJV}}\right)$. However, there is no significant difference of AUC or DSt between the two different catheter positions. In addition, $\mathrm{CO}$ is calculated based on the AUC of thermodilution curve, whereas GEDV and EVLW are calculated by means of CO, MTt, and DSt according to the formulas: $\mathrm{GEDV}=\mathrm{CO} \times(\mathrm{MTt}-\mathrm{DSt})$ and $\mathrm{EVLW}=\mathrm{ITTV}-1.25 \times$ GEDV, provided by PiCCO's instruction manual. Therefore, it can explain the overestimation of GEDVI, and since ITBV is equal to $1.25 \times \mathrm{GEDV}$, ITBVI was also overestimated. Furthermore, since the formulation of EVLW could be converted to $\mathrm{CO} \times(1.25 \times \mathrm{DSt}-0.25 \times \mathrm{MTt})$, we inferred that the factor $0.25 \times \mathrm{MTt}$ is too small to affect the clinical relevant results of EVLWI.

Why was $\mathrm{MTt}_{\mathrm{SCV}-\mathrm{IJV}}$ higher than $\mathrm{MTt}_{\mathrm{IJV}}$ ? We believe that the cold saline has flowed into the jugular vein in the opposite direction after injection into the misplaced SCV catheter distal lumen, and then moved back to the superior vena cava. Therefore, the transit time was delayed because of the longer distances of transmission and this may affect the results of TPTD measurements (Fig. 4).

In the intensive care unit, SCV access has been regarded as the optimal way for central venous cannulation. However, at times, malposition of the SCV catheter occurs and is not detected in time. What causes the delay? Here are some possibilities: (1) Some hospitals in poor areas still lack a mobile radiography machine, and critically ill patients are taken into the digital radiography (DR) room for a chest X-ray, which may bring more risks. (2) Some clinicians have little awareness of the importance of the correct position of the catheter. They always think
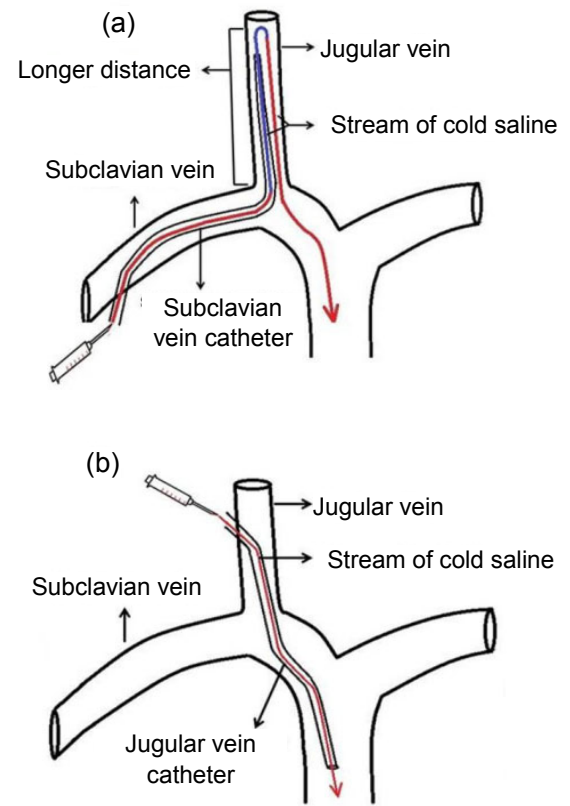

Fig. 4 Superior vena cava catheter position of misplaced subclavian vein catheter (a) and internal jugular vein catheter (b)

Blue line in (a) indicates the longer distance of cold saline via the misplaced catheter (Note: for interpretation of the references to color in this figure legend, the reader is referred to the web version of this article)

that pneumothorax, hemothorax, and air embolism are the most common clinical complications. Therefore, the chest X-ray is often replaced with auscultation and clinical manifestations. In addition, a chest $\mathrm{X}$-ray is regarded as time-consuming and exposes the patient to radiation. (3) In the case of an emergency, matters are too urgent, so there is no time to have a chest X-ray. Our study showed that the misplacement of SCV catheter could affect the results of TPTD measurements. Therefore, the correct position of the SCV catheter should be confirmed by chest X-ray if TPTD measurements are needed.

Furthermore, it is also important to increase the success rate of catheterization. Several studies have reported that there are other tests which can identify the misplacement of an SCV catheter. The IJV vein occlusion test and the saline flush test are the most common methods for rapid diagnosis of a misplaced SCV into the IJV (Ambesh et al., 2001; Rath et al., 2009). Electrocardiograph (ECG) guiding for catheterization of SCV can decrease the malposition, but this method is not advisable for a patient with rhythm 
disturbance (Starr and Cornicelli, 1986; Goel et al., 2010). In addition, it is implicit for misplacement that there is ear pain in the process of catheterization (Dubey and Kumar, 2002).

Based on the results of study, the clinicians have an additional reason for a correct SCV catheter position for obtaining accurate TPTD measurements. Physicians should have a basic and experiential judgment on patients' circulatory state before TPTD is performed, and have awareness to the obvious unusual parameter. Moreover, when an SCV catheter is available, physicians should be sure to have both the ability and methods to avoid misplacing the catheter into the jugular vein.

\section{Conclusions}

The present study showed the influence on TPTD measurements after cold saline injection via a misplaced SCV catheter compared with IJV. Our data indicated that there were overestimations of GEDVI and ITBVI after such misplacement. However, the CI and EVLWI demonstrated an acceptable level of agreement after SCV and IJV injection. Thus, the correct position of SCV catheter is important, and a chest X-ray is necessary. Furthermore, the other tests can increase the success rate of SCV catheterization.

\section{Compliance with ethics guidelines}

Wen-qiao YU, Yun ZHANG, Shao-yang ZHANG, Zhong-yan LIANG, Shui-qiao FU, Jia XU, and Ting-bo LIANG declare that they have no conflict of interest.

All procedures followed were in accordance with the ethical standards of the responsible committee on human experimentation (institutional and national) and with the Helsinki Declaration of 1975, as revised in 2008 (5). Informed consent was obtained from all patients for being included in the study.

\section{References}

Ambesh, S.P., Pandey, J.C., Dubey, P.K., 2001. Internal jugular vein occlusion test for rapid diagnosis of misplaced subclavian vein catheter into the internal jugular vein. Anesthesiology, 95(6):1377-1379. http://dx.doi.org/10.1097/00000542-200112000-00016

Banks, P.A., Bollen, T.L., Dervenis, C., et al., 2013. Classification of acute pancreatitis-2012: revision of the Atlanta classification and definitions by international consensus. Gut, 62(1):102-111.

http://dx.doi.org/10.1136/gutjnl-2012-302779
Belda, F.J., Aguilar, G., Teboul, J.L., et al., 2011. Complications related to less-invasive haemodynamic monitoring. $B r . J$. Anaesth., 106(4):482-486. http://dx.doi.org/10.1093/bja/aeq377

Bendjelid, K., Giraud, R., Siegenthaler, N., et al., 2010. Validation of a new transpulmonary thermodilution system to assess global end-diastolic volume and extravascular lung water. Crit. Care, 14(6):R209. http://dx.doi.org/10.1186/cc9332

Cannesson, M., Pestel, G., Ricks, C., et al., 2011. Hemodynamic monitoring and management in patients undergoing high risk surgery: a survey among North American and European anesthesiologists. Crit. Care, 15(4):R197. http://dx.doi.org/10.1186/cc10364

Della Rocca, G., Costa, M.G., Pompei, L., et al., 2002. Continuous and intermittent cardiac output measurement: pulmonary artery catheter versus aortic transpulmonary technique. Br. J. Anaesth., 88(3):350-356. http://dx.doi.org/10.1093/bja/88.3.350

Della Rocca, G., Costa, M.G., Pietropaoli, P., 2007. How to measure and interpret volumetric measures of preload? Curr. Opin. Crit. Care, 13(3):297-302. http://dx.doi.org/10.1097/MCC.0b013e32811d6ce3

Dubey, P.K., Kumar, H., 2002. Pain in the ear resulting from misplaced subclavian dialysis catheter into ipsilateral internal jugular vein. Anesth Analg, 94(6):1460-1461. http://dx.doi.org/10.1213/00000539-200206000-00014

Eichhorn, V., Goepfert, M.S., Eulenburg, C., et al., 2012. Comparison of values in critically ill patients for global end-diastolic volume and extravascular lung water measured by transcardiopulmonary thermodilution: a metaanalysis of the literature. Med. Intensiva, 36(7): 467-474. http://dx.doi.org/10.1016/j.medin.2011.11.014

Goel, S., Tandon, M., Panigrahi, B., 2010. Bedside technique to detect misplaced subclavian vein catheter in internal jugular vein. Ann. Card. Anaesth., 13(1):71-72. http://dx.doi.org/10.4103/0971-9784.58841

Heid, F., Muller, N., Piepho, T., et al., 2008. Postoperative analgesic efficacy of peripheral levobupivacaine and ropivacaine: a prospective, randomized double-blind trial in patients after total knee arthroplasty. Anesth. Analg., 106(5):1559-1561. http://dx.doi.org/10.1213/ane.0b013e318168b493

Katzenelson, R., Perel, A., Berkenstadt, H., et al., 2004. Accuracy of transpulmonary thermodilution versus gravimetric measurement of extravascular lung water. Crit. Care Med., 32(7):1550-1554. http://dx.doi.org/10.1097/01.CCM.0000130995.18334.8B

Khan, S., Trof, R.J., Groeneveld, A.B., 2007. Transpulmonary dilution-derived extravascular lung water as a measure of lung edema. Curr. Opin. Crit. Care, 13(3):303-307. http://dx.doi.org/10.1097/MCC.0b013e32811d6ced

Kiefer, N., Hofer, C.K., Marx, G., et al., 2012. Clinical validation of a new thermodilution system for the assessment of cardiac output and volumetric parameters. 
Crit. Care, 16(3):R98.

http://dx.doi.org/10.1186/cc11366

Kuzkov, V.V., Kirov, M.Y., Sovershaev, M.A., et al., 2006. Extravascular lung water determined with single transpulmonary thermodilution correlates with the severity of sepsis-induced acute lung injury. Crit. Care Med., 34(6):1647-1653. http://dx.doi.org/10.1097/01.CCM.0000218817.24208.2E

Michard, F., Schachtrupp, A., Toens, C., 2005. Factors influencing the estimation of extravascular lung water by transpulmonary thermodilution in critically ill patients. Crit. Care Med., 33(6):1243-1247.

http://dx.doi.org/10.1097/01.CCM.0000164566.23147.35

O'Grady, N.P., Alexander, M., Burns, L.A., et al., 2011. Guidelines for the prevention of intravascular catheterrelated infections. Clin. Infect. Dis., 52(9):e162-e193. http://dx.doi.org/10.1093/cid/cir257

Rath, G.P., Bithal, P.K., Toshniwal, G.R., et al., 2009. Saline flush test for bedside detection of misplaced subclavian vein catheter into ipsilateral internal jugular vein. $B r . J$. Anaesth., 102(4):499-502. http://dx.doi.org/10.1093/bja/aep021

Reuter, D.A., Felbinger, T.W., Schmidt, C., et al., 2005. Trendelenburg positioning after cardiac surgery: effects on intrathoracic blood volume index and cardiac performance. Eur. J. Anaesthesiol., 20(1):17-20. http://dx.doi.org/10.1017/S0265021503000036

Sakka, S.G., Bredle, D.L., Reinhart, K., et al., 1999. Comparison between intrathoracic blood volume and cardiac filling pressures in the early phase of hemodynamic instability of patients with sepsis or septic shock. J. Crit. Care, 14(2):78-83. http://dx.doi.org/10.1016/S0883-9441(99)90018-7

Sakka, S.G., Reuter, D.A., Perel, A., 2012. The transpulmonary thermodilution technique. J. Clin. Monit. Comput., 26(5):347-353. http://dx.doi.org/10.1007/s10877-012-9378-5

Saugel, B., Umgelter, A., Schuster, T., et al., 2010. Transpulmonary thermodilution using femoral indicator injection: a prospective trial in patients with a femoral and a jugular central venous catheter. Crit. Care, 14(3):R95. http://dx.doi.org/10.1186/cc9030

Schmidt, S., Westhoff, T.H., Hofmann, C., et al., 2007. Effect of the venous catheter site on transpulmonary thermodilution measurement variables. Crit. Care Med.,
35(3):783-786.

http://dx.doi.org/10.1097/01.CCM.0000256720.11360.FB

Starr, D.S., Cornicelli, S., 1986. EKG guided placement of subclavian CVP catheters using J-wire. Ann. Surg., 204(6):673-676.

http://dx.doi.org/10.1097/00000658-198612000-00009

Vincent, J.L., Rhodes, A., Perel, A., et al., 2011. Clinical review: update on hemodynamic monitoring - a consensus of 16. Crit. Care, 15(4):229.

http://dx.doi.org/10.1186/cc10291

\section{中文概 要}

\section{题 目: 锁骨下静脉导管误入颈内静脉对热稀释测量数据 的影响}

目 的: 临床上锁骨下静脉导管误入颈内静脉时有发生, 但错误导管位置是否对 PiCCO 监测数据结果有 影响, 从而导致临床医生对患者病情出现误判目 前尚不清楚。本研究的主要目的是观察错误导管 位置对 $\mathrm{PiCCO}$ 数据 (如全心舒张末容积指数 (GEDVI) 、血管外肺水指数（ELWI）、胸腔 内血容积指数 (ITBVI) 和心指数 (CI)) 的影响。

创新点: 目前临床医生对锁骨下静脉导管的位置不够重 视, 更不会了解错误导管对临床血流动力学监测 的影响, 从而做出错误的临床决策。本研究提出 错误导管位置对 PiCCO 数据的影响, 再次强调确 认正确锁骨下静脉导管位置的重要性, 并提出如 何判断导管在正确位置的床边小技巧。

方 法: 本研究回顾性分析 13 例重症胰腺炎病人接受错 误导管位置的 PiCCO 测量后, 与正确位置导管的 PiCCO 数据进行对比, 分析错误导管位置对 PiCCO 数据包括 GEDVI、ELWI、ITBVI 和 CI 的影响。

结 论: 错误的锁骨下静脉导管导致 GEDVI 和 ITBVI 数 据偏高, 而对 CI 及 ELWI 的影响无统计学意义, 因此, 正确的导管位置对临床 PiCCO 监测的数据 很重要。

关键词: 经肺热稀释; 颈内静脉导管; 错误的锁骨下静脉 导管; 重症急性胰腺炎 